\title{
ATTRACTIVE STREETSCAPE MAKING PEDESTRIANS WALK LONGER ROUTES: THE CASE OF KUNITACHI IN TOKYO
}

\author{
Marco CAPITANIO* \\ Graduate School of Science and Technology, Keio University, Address: 3-14-1 Hiyoshi, Kohoku-ku, \\ Yokohama, Kanagawa 223-8522, Japan
}

Received 17 January 2018; accepted 10 January 2019

\begin{abstract}
There are manifold benefits of an increase in pedestrian movement, both in regard to societal and to personal wellbeing, and walkability is considered a major goal in urban design. However, it is methodologically complicated to ascertain to what extent streetscape features relating to comfort and pleasurability influence pedestrian behavior. Our hypothesis is that pedestrians, at the neighborhood scale, prefer more attractive routes even if they are longer than other possible and equally safe routes to reach a certain destination, independently of the presence of amenities. As a case study, we selected Kunitachi, an attractive city in Tokyo Prefecture, thus adding to the body of non-western empirical research on pedestrian preferences. By comparing two Space Syntax betweenness simulations of pedestrian routes - compulsory and optional - with an actual counting of pedestrian frequency on site, and with behavioral observations, we have established that simulations according to the principle of "shortest route" considerably differ from actual pedestrian frequency. Only by allowing a certain detour leeway, simulations showed a less pronounced discrepancy with reality. While further research is needed to confirm our results, this enquiry has demonstrated that, attractive streetscape features are part of the reason why local residents prefer pleasant and comfortable routes over shorter ones.
\end{abstract}

Keywords: walkability, attractive streetscape, pedestrian frequency, Space Syntax, betweenness, Kunitachi.

\section{Introduction}

The pedestrian environment could be considered a sort of glue holding neighborhoods and cities together, relating to different factors, such as accessibility, quality of outdoor spaces, street character and usage. There are manifold benefits of an increase in pedestrian movement, both in regard to societal and to personal wellbeing. Encouraging pedestrian movement is a commonly deployed strategy when aiming at creating sustainable, interesting and vital urban milieus, and at improving the wellness of the population (Takano, Nakamura, \& Watanabe, 2002). Moreover, attractive pedestrian environments are also linked to clear economic benefits, as financial returns derived from land or property value increase along lively and high-quality streets (CABE, 2007). A compact urban form and mixed uses alone, though, cannot guarantee an increase of pedestrian frequency or of walked distance, if they are not sustained by comfortable and pleasant streetscape.
Given the numerous factors involved - degree of openness of a settlement, quality and character of connections at ground floor, presence of gates, fences or greenery, type and amount of amenities, etc. - it is methodologically complicated to ascertain to what extent streetscape features relating to comfort and pleasurability influence pedestrian behavior. While there is extensive literature on design principles for good street design (Massengale \& Dover, 2013; Talen, 2002; Jacobs, 1995) and on building codes promoting walkability (Hansen, 2014; Ewing et al., 2006), results from empirical research are inconsistent. Moreover, a variety of research methods, hard-to-compare cultural specificities and different disciplinary standpoints call for more context-grounded investigations. Among the existing literature on the influence of environmental elements on walkability and route choice it shall here suffice to refer to the following two research projects. On the one hand, Adkins, Dill, Luhr, and Neal (2012), employing a surveybased method to assess walkability in a single-family

${ }^{*}$ Corresponding author. E-mail: capitanio@keio.jp 
residential environment in Portland (OR) highlighted the positive role played by well-designed greenery and sidewalks, and good pedestrian connectivity, on the attractiveness of streets. On the other hand, Foltête and Piombini (2007) used a combined research method featuring Space Syntax and GIS-obtained routes of a relevant number of pedestrians. In this case, route choices by pedestrians were explained and tested in regard to accessibility - expressed with the "integration index" or "depth" in Space Syntax and to attractiveness or "preference" variables. While the authors suggested that landscape features influence pedestrian behavior, they concluded that "it is not certain that the promotion of landscapes appreciated by pedestrians can stimulate movement." (ivi, p. 233) It is therefore our goal to provide more evidence on walking preferences and test whether pedestrians pick more attractive routes over shorter ones at the neighborhood scale, in a non-western urban context like that of Tokyo. The decade-long empirical enquiry by Gehl (2013), in fact, mainly deals with outdoor activities and ways to support them, but does not systematically assess to which degree certain streetscapes can make people walk longer-than-necessary routes.

From the point of view of urban design, in principle, interconnected streets and pathways are preferable over cul-de-sac and dead-end streets, which do not encourage transit. In concrete terms, though, a so-called fused grid (a mixture between a classical grid and a Radburn pattern ${ }^{1}$ ) can be seen as a way to assure enough permeability for pedestrians while limiting the negative externalities of traffic, such as noise and pollution. Nonetheless, the meaning and long tradition of Asian alleyways (e.g. Japanese roji; Shanghainese lilong) or enclosed spaces (e.g. Beijing's hutong) suggest that perception of streetscape quality is relative to specific socio-cultural values (Radović, 2016), and that a maximum degree of openness and permeability is not always beneficial or desirable. As such, there is a need to assess streetscapes in different contexts, and a normative and all-encompassing standpoint is to be avoided.

Moreover, invisible, psychological factors can play a relevant role in the quality of streetscapes. According to Mandanipour (2016), accessibility is regulated by essentially three kinds of barriers. First, physical barriers, e.g. fences and walls. Second, perceived barriers like codes and signs, as "we may be hesitant to enter an expensivelooking shopping center if we do not have access to the resources needed for the activities there". Third, social control, e.g. legal prohibitions.

The purpose of walking affects pedestrian behavior in the first place. In this respect, Gehl (1987, pp. 11-13) distinguishes between two types of activities in outdoor public space. On the one hand, there are compulsory

\footnotetext{
1 Radburn (NJ) was built in 1928 by the Regional Planning Association of America as an experimental residential community. Its masterplan features a bent grid of major thoroughfares and a finer mesh of gently curving dead-end residential streets.
}

ones, which will happen regardless of spatial quality, weather conditions, etc., e.g. going to work. On the other hand, there are optional ones, that may or may not happen, depending on specific characteristics of the location, e.g. an evening stroll. When considering the intensity of optional activities it is possible, according to Gehl, to understand how appreciated and successful a park, square or street is.

\section{Aim and methods}

Our research hypothesis is that pedestrians choose to walk more attractive routes even if they are longer than other possible and equally safe ways to reach a certain destination. This runs against the assumption of certain Space Syntax simulations predicting pedestrian flow based on shortest routes, but echoes an increasing body of literature exposing the existence of multifarious walking needs. From this point of view, we intend to assess whether qualitative attractiveness of streetscape can be more important than quantitative walking distance when choosing - often unconsciously - a walking route. It is important to note that "attractiveness" refers, in this case, to the morphological built and natural features of streetscape relating to pleasurability, and not to the presence or absence of amenities. The research design features first a comparison between Space Syntax simulations of pedestrian flow and the actual counting of pedestrian frequency on-site, using the so-called "gate" method (Gehl \& Svarre, 2013, p. 25). Since both compulsory and optional routes are simulated, taking into account the presence of amenities along the street network, our assumption is that discrepancies between simulated flow and actual pedestrian frequency can be explained by variables relating to streetscape attractiveness. In other words, assuming Alfonzo's (2005) hierarchy of five walking needs - feasibility, accessibility, safety, comfort and pleasurability - we intend to test whether the supposedly weaker walking needs of comfort and pleasurability can influence route choice at the detriment of accessibility in terms of walking distance. For this purpose, feasibility and safety have been disregarded. The former, in fact, does not play any role in the choice of different walking routes, as it determines whether an individual decides to walk, to use another means of transportation, or not to travel at all. The latter can be considered irrelevant in the uniformly safe Japanese urban environment.

Space Syntax is a spatial and analytical theory developed by Hillier and Hanson (1984) at Bartlett University, London. It is mainly used to assess the (intel)legibility of street networks and the accessibility of points (e.g. representing buildings) along given routes. For this research, we have used the software "Rhino UNA toolbox" developed by City Form Lab (Sevtsuk, 2016) at MIT. This software was specifically programmed to be used by architects and planners, as it enables a seamless workflow between design, analysis and simulation of spatial configurations. 
Among the many types of Space Syntax analysis, we have focused on betweenness to simulate pedestrian flows (Offenhuber \& Ratti, 2014, p. 12), rather than examining the "integration index" or "depth" of the street network.

Betweenness "approximates by-passing traffic or footfall at particular locations in a spatial network. The Betweenness of a building is defined as the fraction of shortest paths between pairs of other origins and destinations in the network that pass by a particular location" (City Form Lab, 2015, p. 23). In our case study, we will simulate pedestrian flow between I) all residential \& office buildings and a train station; II) commercial activities and a train station. The former aims at simulating commuters' (compulsory) routes, while the latter aims at simulating shoppers' (optional) routes. After a shortest-path simulation, we will run betweenness with detour ratios, i.e. including in the calculation routes longer than shortest paths by a given percentage ${ }^{2}$. Betweenness analysis will be "weighted", i.e. the buildings' number of floors will influence outcomes, generating a proportional amount of simulated pedestrian routes ${ }^{3}$. These results will be compared with actual pedestrian frequency, measured on-site, leading to a morphological and behavioral assessment of streetscape attractiveness along representative route segments.

\section{Case study: Kunitachi}

Kunitachi (国立市) is a city ca. $30 \mathrm{~km}$ (45 minutes by train) west of Tokyo Station, lying in the Tama Area. Despite its peripheral location, the city is considered convenient to live in and attractive, as a 2012 survey confirms (Osanai, 2012, p. 70): in fact, while Kunitachi ranks number 28 among Tokyo neighborhoods where people would

2 "The Betweenness algorithm in the Rhino UNA toolbox has been specifically customized to make it useful and practical for estimating realistic pedestrian movement in spatial networks. Whereas a traditional Betweenness index would estimate trips from a set of origins to a set of destinations along shortest paths, keeping track of how many trip follow each route, the Betweenness algorithm in the Rhino UNA toolbox allows you to relax the shortest path assumption. A "DetourRatio" variable allows walks between origins and destinations to deviate up to the specified \% above the shortest paths (the maximum deviation is fixed at 200\%). Using a DetourRatio of " 1.1 ", for instance, allows walks to use paths that are up to $10 \%$ longer than the shortest path to reach the destination. Each alternative path that is found is given an equal likelihood, dividing the weights of the Origin point equally between all alternative paths." (City Form Lab, 2015, p. 24).

3 "Weights allow you to weight the analysis according to the properties of origin points. If an origin point has a weight of " 100 " for instance, describing its number of residents, then weighted Betwenness will route 100 trips from the origin location to the destination, instead of just one trip." (City Form Lab, 2015, p. 24) In our case, buildings with 1-3 floors will count as 1 , buildings with $4-6$ floors as 10 , buildings with 7-10 floors as 17 and buildings with $10+$ floors as 24 . like to live in, it is the 7th best place among areas where respondents have actually lived. It was founded as a new town, developed by Tsutsumi Yasujirō, business tycoon and politician. He started buying land in the early 1920s with the vision of establishing a university town, following the model of Göttingen in Germany. When the 1923 Great Kantō Earthquake struck, he proposed to the president of the Tokyo College of Commerce (later renamed Hitotsubashi University) and of the Tokyo Higher School of Music to abandon their damaged properties in central Tokyo and move to the western, leafy suburbs, to a new town akin to Howard's garden city model (Osanai, 2012). 1926 marked the opening, on the JR Chūō Railway Line, of Kunitachi Station, which constituted the focal point of three radial, convergent streets cutting-through a city grid composed of 250x75m blocks (Figure 1). The central artery (Daigaku-dōri), connecting the train station with Hitotsubashi University, was conceived as a Europeanstyle boulevard, featuring broad sidewalks lined with cherry and ginkgo trees.

Over the years, Kunitachi has gained the reputation of a child-friendly and attractive town (Molasky, 2014, p. 72), mostly due to its unique streetscape (Tsugawa, 2014). The neat city grid, pierced by three diagonal streets, and the exceptional level of comfort, pleasurability and attractiveness of its central boulevard, constitute an ideal model where to prove our hypothesis that, at the neighborhood scale, more attractive streets are preferred over shorter but less attractive ones. In the case of Kunitachi, we will test whether simulated and actual pedestrian presence coincide, and whether Daigaku-dōri hosts a larger-thansimulated number of passers-by, due to its unique features compared to the rest of the city grid.

Figure 2 shows the distribution of uses and the morphological characteristics of Kunitachi. Commercial activitis are clustered around the train station and along the three main radial axes. Hitotsubashi University Campus acts as a public park, marking a stark contrast with the low-rise, moderately dense but compact urban tissue.

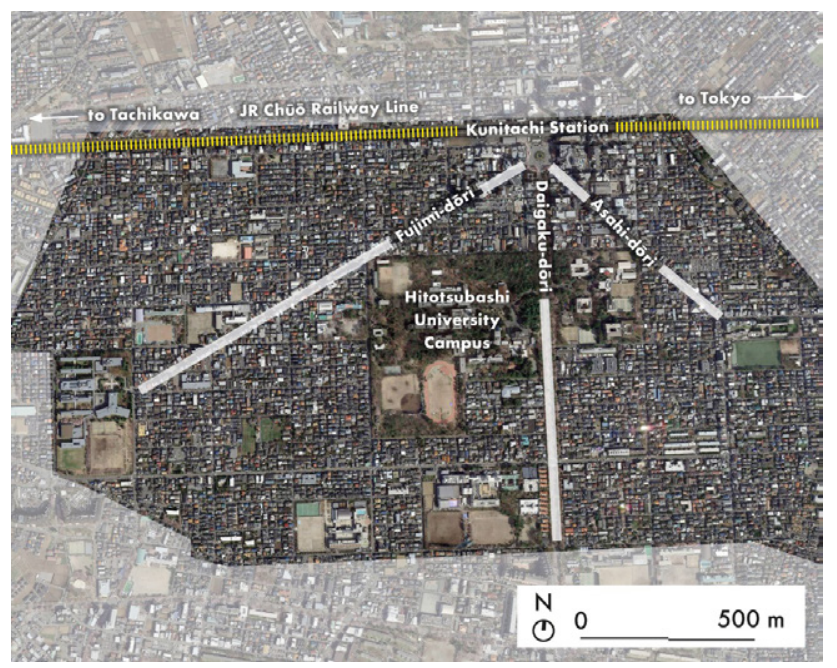

Figure 1. Aerial view of Kunitachi 


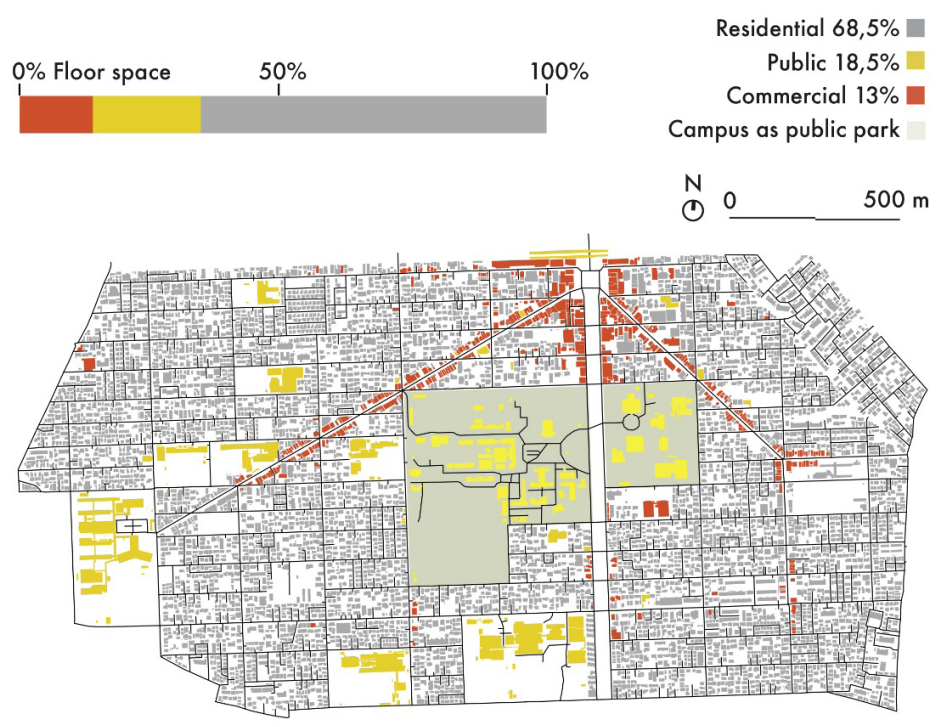

Figure 2. Activities' distribution in Kunitachi. The color bar refers to the total floor space. The mapping was compiled according to on-site surveys

Noteworthy is the floor-space percentage of public uses $(18,5 \%)$ : in fact, numerous educational institutions dot the city, strengthening the image of a college town.

\section{Results}

Given the comparable geometrical layout of the three radial streets, we decided to focus on three street segments indicated by the yellow dots in Figure 5. A betweenness simulation was first carried out. Targeting compulsory routes, in the first simulation Ia) (Figure 3a) all residential and office buildings represented origins, weighted according to the number of floors, while Kunitachi Station represented a single destination; routes were calculated according to shortest paths. Within a maximum value of 9256 routes and a minimum of 1 Fujimi-dori (at the segment corresponding to the "gate" method counting, see below) reached 3158, Daigaku-dōri $540 \& 464^{4}$ and Asahidōi 2339. We proceeded with a further iteration Ib) (Figure 3b), where betweenness analysis allowed routes up to $20 \%$ longer (detours) than shortest paths. In this case, while passers-by were still predicted to be more numerous on Fujimi- and Asahi-dōri, the difference with Daigakudōri was less pronounced: Fujimi-dōri 1422; Daigaku-dōri 941 \& 643; Asahi-dōri 1679.

Targeting optional routes, in the second simulation a) (Figure 4a) commercial activities represented origins, weighted according to the number of floors, while Kunitachi Station represented a single destination; routes were calculated according to shortest paths. Once again, Fujimi- and Asahidōri were predicted to be the main thoroughfares, assigning to Daigaku-dōri a marginal role: Fujimi-dōri 157; Daigakudōri 53 \& 43; Asahi-dōri 174. In a further iteration b)

\footnotetext{
4 There are two values as Daigaku-dōri was drawn with two
} lines, representing the left and right sidewalks.

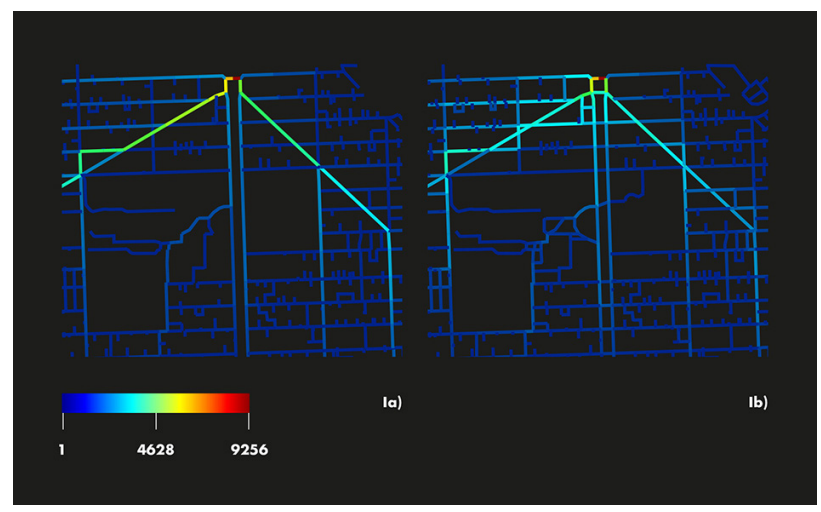

Figure 3. a) Betweenness simulation; residential \& office buildings as origins; train station as destination; shortest path; weighted to the number of floors; b) Betweenness simulation; residential \& office buildings as origins; train station as destination; $20 \%$ detour; weighted to the number of floors

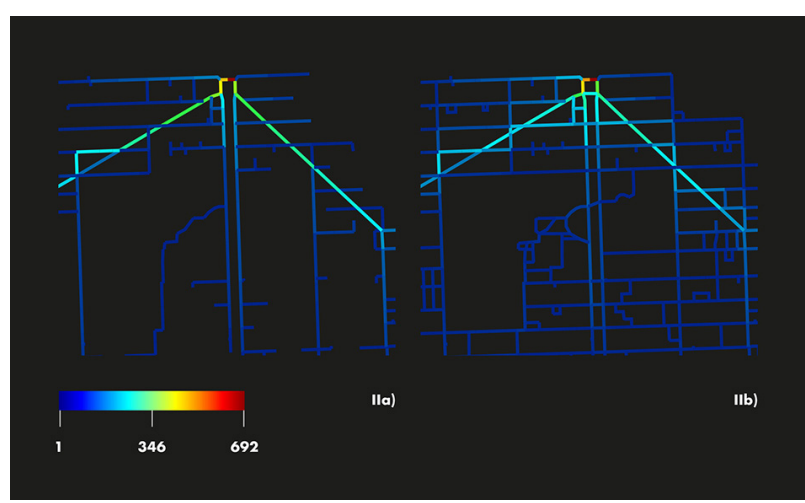

Figure 4. a) Betweenness simulation; commercial activities as origins; train station as destination; shortest path; weighted to the number of floors; b) Betweenness simulation; commercial activities as origins; train station as destination; $20 \%$ detour; weighted to the number of floors 


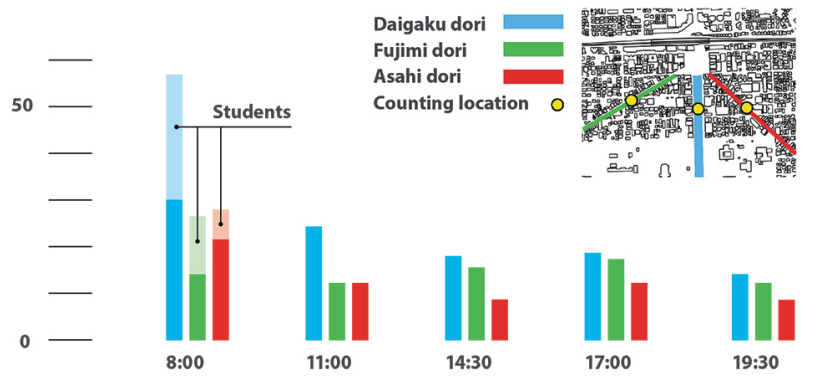

Figure 5. "Gate" method counting of pedestrian frequency on-site

(Figure 4b), betweenness analysis allowed routes up to $20 \%$ longer than shortest paths. In this case, passers-by were evenly distributed among the three radial streets: Fujimidōri 93; Daigaku-dōri 77 \& 44; Asahi-dōri 139.

We proceeded with the actual counting of pedestrian frequency using the "gate" method. We counted the number of pedestrians over a time-span of one minute at a fixed location (corresponding to the segment considered in the betweenness simulation) on Fujimi-, Daigaku- and Asahi-dōri. The counting was performed five times from 8 am to 7:30 pm, on a sparsely cloudy weekday with mild temperatures, in early October 2016, repeating a 1-minute counting session twice. In the betweenness simulation, Daigaku-dōri was drawn with two parallel lines, indicating the left and right sidewalks, and therefore the number of pedestrians counted with the "gate" method has been halved. The results show how Daigaku-dōri consistently hosted more passers-by in every pedestrian-frequency counting (Figure 5). Even leaving aside students (who flock to Hitotsubashi University's entrance, located on Daigaku-dōri, and therefore do not have any alternative route), people on Daigaku-dōri outnumbered those walking along the other two radial streets.

The final step of our analysis introduced morphological characteristics of the three radial streets, exposing the presence or lack of elements of comfort and pleasurability for pedestrians (Figure 6). The central boulevard, a true unicum in Japan, is $44 \mathrm{~m}$-wide, including a $3.6 \mathrm{~m}$-wide sidewalk with ample room for pedestrians and sitting space. It features abundant greenery of various height and kind, while rows of 100 year-old ginkgo biloba and cherry trees on each side provide shade all day long. In spring, the lawns under Daigaku-dōri's cherry trees are popular spots for hanami (cherry-blossom viewing), as families and friends spread their sheets on the grass. It also hosts some sculptures created for the 2015 Kunitachi Art Biennale. Fujimi- and Asahi-dōri have, in contrast, a more conventional and nondescript character, lack greenery of any kind and feature narrow sidewalks. Moreover, their width-height proportion (ca. 1:1) considerably differs from that of Daigaku-dōi (ca. 2:1).

\section{Discussion}

In our hypothesis, Daigaku-dōri, being the main boulevard with unique and attractive morphological features, was expected to host the highest amount of pedestrians, despite not being, as seen in betweenness analysis, the shortest route for most of the simulated routes. On-site counting of pedestrian frequency confirmed the hypothesis, but considerably differed from simulated pedestrian flows of standard betweenness analysis. Only by allowing a certain detour ratio could betweenness approximate observed pedestrian frequency. Behavioral observations can further clarify the reasons behind this discrepancy, attributable to streetscape attractiveness. In fact, people do not use Daigaku-dōri just as a thoroughfare, but they perceive the street as a destination in itself. Its broad sidewalk, protected from traffic by greenery and trees, is an amenity especially for the elderly and parents with children. Moreover, local kindergartens take out children every day during the good season for a walk through Daigaku-dōri to Hitotsubashi University Campus (Figure 7). During a personal interview, in fact, a kindergarten teacher stated that many parents deliberately walk through Daigaku-dōri to the kindergarten because of its streetscape qualities, compared to shorter routes.
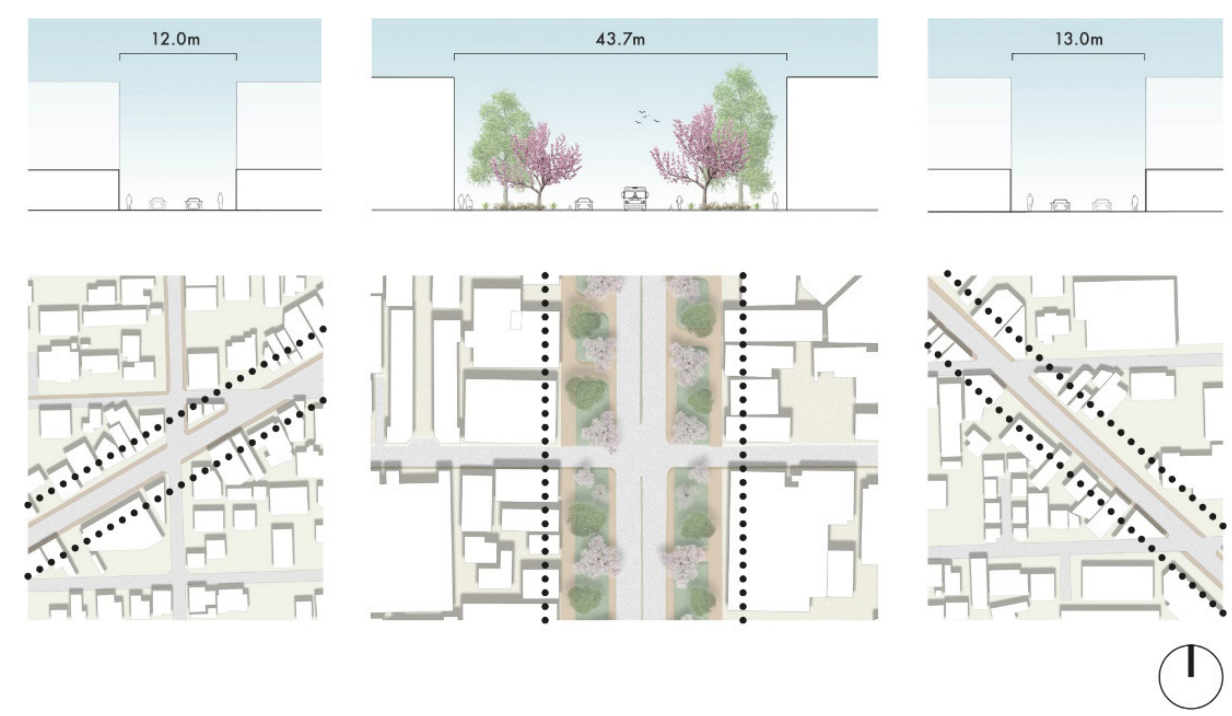

Figure 6. From left to right sections (above) and plans (below) of Fujimi-, Daigaku- and Asahi-dōri 

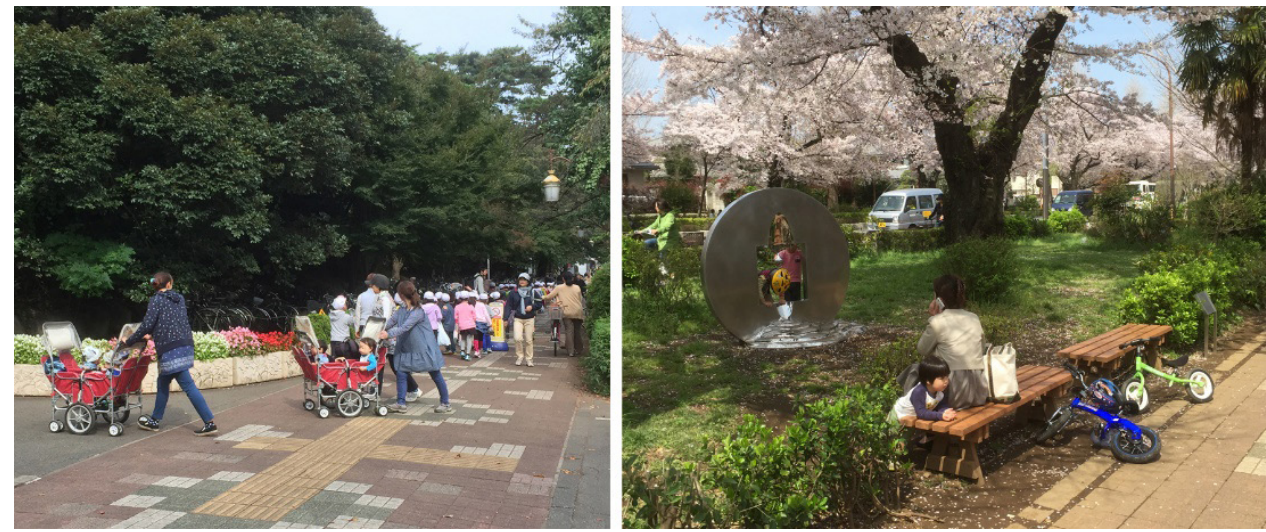

Figure 7. On the left, a kindergarten class walking along Daigaku-dōri; on the right, Daigaku-dōri as a playground
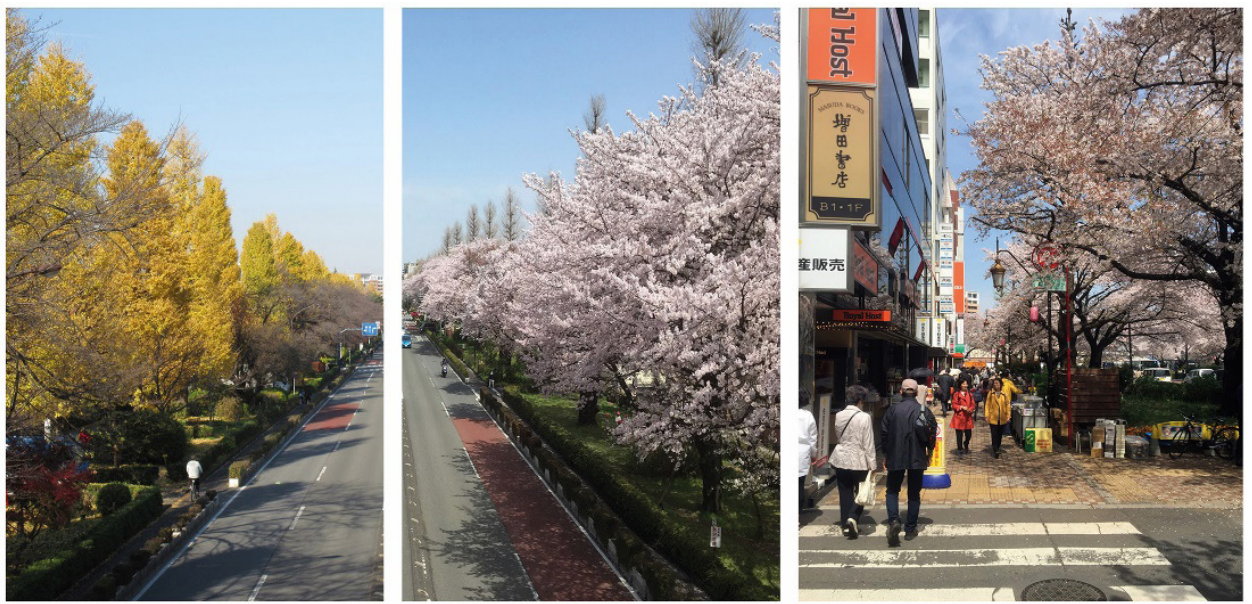

Figure 8. Seasonal variations and versatility of Daigaku-dōri. Scenery in autumn on the left; scenery in spring in the center; eye-level shot on the right

The landscape design, featuring ginkgo and cherry trees, allows for a radical change of scenery, when cherry trees bloom in spring and ginkgo turn yellow in autumn, thus linking the street with cultural traditions such as hanami and autumn leaves celebrations. Lastly, the wide sidewalk can host a number of informal activities, most notably a row of temporary stalls when local festivals (matsuri) are taking place (Figure 8). People like to go to Daigaku-dōri because of its morphological qualities related to comfort and pleasurability: this street is versatile, and can host multifarious activities, changing according to the seasons. It is a destination in itself, contributing to $\mathrm{Ku}$ nitachi's uniqueness, where people can sit and spend time, walk with strollers at ease thanks to wide sidewalks, be in contact with greenery and protected from sunshine, shop.

In the case of Daigaku-dōri, people tend to walk routes considerably longer than the shortest possible path. Given technical computational limitations of the software and the devised research method, it was not possible to determine an exact range of length increase, but our results indicate that an attractive route is preferred over a nonattractive, $20 \%$ shorter one.

\section{Conclusions}

The aim of this research was to test whether pedestrians favor more attractive routes even if they are longer than other possible and equally safe routes to reach a certain destination, independently of the presence of amenities. As a case study, we picked a Japanese neighborhood, thus adding to the body of non-western empirical research on pedestrian preferences. We have chosen the neat city grid of Kunitachi, west of Tokyo, pierced by three radial streets departing from a train station. The central boulevard, Daigaku-dōri, has exceptional morphological features, making it stand out in the otherwise regular urban tissue, and constituting an ideal case where to test the influence of elements of comfort and pleasurability on route choice. By comparing two Space Syntax betweenness simulations of pedestrian flow with "gate" method measurements on site, we have established that simulations according to the principle of "shortest route" considerably differ from actual pedestrian frequency. By allowing a certain detour leeway, i.e. computing routes longer that the shortest option by a given percentage, simulation results showed a less pronounced discrepancy with reality. This implies that people in Kunitachi tend not to choose shortest routes to walk to the train station or to reach commercial activities. 
By examining the morphological features of the three radial streets, and by means of behavioral observations, we have concluded that the exceptional attractiveness of Daigaku-dori is the reason behind the exposed discrepancy of results. Its aesthetic changes in different seasons and high affordance of various (informal) uses, presence of abundant shading greenery of different kind and height, sitting opportunities and broad sidewalks make it a destination in itself. From this point of view, public and private investment toward more high-quality pedestrian environment can be directly related to longer walks (but not necessarily to an increase in walking trips overall), with benefits to neighborhood liveability and to the wellbeing of the population.

This research was limited to one case study in Japan. As argued in the introductory section, different places and cultures have different attitudes toward the use and meaning of the pedestrian environment. While further research in other parts of Japan and other countries is needed to confirm our results, this enquiry suggests that, in the case of Tokyo's residential areas, people favor attractive, pleasant and comfortable routes over shorter ones. We do not question here the validity of the hierarchy-of-walkingneeds model (Alfonzo, 2005), but our research indicates that such hierarchy has to be always tested against local socio-cultural traits. Moreover, the role of human perception and emotional response to the environment unconsciously determines pedestrian preferences, as everyone has surely experienced. In fact, an attractive route may indeed appear to be shorter, despite being longer in terms of travel distance. From this point of view, further research employing big data analysis and surveys, tested against simulation models, is needed to better explore the linkages between conscious and unconscious walking preferences.

\section{Acknowledgements}

I would like to express my gratitude to Prof. Darko Radović and Prof. Davisi Boontharm: their comments were crucial in refining the structure and content of this paper. Fellow $\mathrm{PhD}$ candidates at co+labo and Dr. Simone Garlandini have offered valuable suggestions for improvement.

This work was supported by GESL Program at Keio University, Tokyo.

\section{Competing interests}

In regard to this research, there are no competing financial, professional, or personal interests.

\section{References}

Adkins, A., Dill, J., Luhr, G., \& Neal, M. (2012). Unpacking walkability: testing the influence of urban design features on perceptions of walking environment attractiveness. Journal of Urban Design, 17(4), 499-510.

https://doi.org/10.1080/13574809.2012.706365
Alfonzo, M. A. (2005). To walk or not to walk? The hierarchy of walking needs. Environment and Behavior, 37(6), 808-836. https://doi.org/10.1177/0013916504274016

CABE. (2007). Paved with gold. The real value of good street design. London: Commission for architecture and built environment.

City Form Lab. (2015). Urban network analysis toolbox for rhinoceros 3D. Cambridge, Massachusetts: Harvard GSD.

Ewing, R., Handy, S., Brownson, R. C., Clemente, O., \& Winston, E. (2006). Identifying and measuring urban design qualities related to walkability. Journal of Physical Activity and Health, 3(1), 223-240. https://doi.org/10.1123/jpah.3.s1.s223

Foltête, J.-C., \& Piombini, A. (2007). Urban layout, landscape features and pedestrian usage. Landscape and Urban Planning, 81, 225-234.

https://doi.org/10.1016/j.landurbplan.2006.12.001

Gehl, J. (1987). Life between buildings. New York: Van Nostrand Reinhold Company.

Gehl, J., \& Svarre, B. (2013). How to study public life. Washington: Island Press. https://doi.org/10.5822/978-1-61091-525-0

Hansen, G. (2014). Design for healthy communities: the potential of form-based codes to create walkable urban streets. Journal of Urban Design, 19(2), 151-170. https://doi.org/10.1080/13574809.2013.870466

Hillier, B., \& Hanson, J. (1984). The social logic of space. Cambridge: Cambridge University Press.

https://doi.org/10.1017/CBO9780511597237

Jacobs, A. (1995). Great streets. Cambridge: The MIT Press.

Madanipour, A. (2016). Social exclusion and space. In R. LeGates \& F. Stout (Eds.), The city reader. London: Routledge.

Massengale, J., \& Dover, V. (2013). Street design: the secret to great cities and towns. Hoboken: Wiley.

Miura, A. (2012). Tōkyō wa kōgai kara kieteiku! Shutoken kōreika mikon-ka akiya chizu [From now on Tokyo is going to disappear starting from the suburbs! Mappings of aging, lack of marriages and vacant houses in Tokyo Metropolitan Area]. Kōbunsha.

Molasky, M. (2014). The American occupation and municipal identity: two towns in western Tokyo. In R. Caroli \& D. Basosi (Eds.), Legacies of the U.S. occupation of Japan: appraisals after sixty years (pp. 66-79). Newcastle upon Tyne: Cambridge Scholars Publishing.

Offenhuber, D., \& Ratti, C. (2014). Decoding the city. Basel: Birkhäuser. https://doi.org/10.1515/9783038213925

Osanai, T. (2012). Kunitachi Daigakumachi no Tanjō [The birth of Kunitachi as a University Town]. Tachikawa-shi, Keyaki Shuppan.

Radović, D. (2016). Measuring the non-measurable: on mapping subjectivities in urban research. City, Culture and Society, 7(1), 17-24. https://doi.org/10.1016/j.ccs.2015.10.003

Sevtsuk, A. (2016). City form lab. Retrieved from http://cityform. mit.edu/en

Takano, T., Nakamura, K., \& Watanabe, M. (2002). Urban residential environments and senior citizens' longevity in megacity areas: the importance of walkable spaces. Journal of Epidemiology \& Community Health, 56, 913-918.

https://doi.org/10.1136/jech.56.12.913

Talen, E. (2002). Pedestrian access as a measure of urban quality. Planning Practice \& Research, 17(3), 275-278. https://doi.org/10.1080/026974502200005634

Tsugawa, Y. (2014). Toshi keikan keisei no purosesu to randomāku no kinō - Tōkyō Kunitachi-shi o jirei ni [Urban landscape formation process and landmark functions: a case study of Kunitachi City in Tokyo]. Chiiki Seisaku Kenkyū 16(3), 135-151. https://doi.org/10.1177/1462474513517016 